\title{
Saneamento rural no Brasil: impacto da fossa séptica biodigestora
}

\author{
Rural sanitation in Brazil: impact analysis of the septic tank digester
}

Cinthia Cabral da Costa', Joaquim José Martins Guilhoto²

口-

\begin{abstract}
RESUMO
O Brasil tem mais de 23 milhões de pessoas na zona rural sem coleta ou tratamento de esgoto, o que corresponde a $75 \%$ da população rural. Este estudo teve como objetivo mensurar os impactos social, ambiental e econômico decorrente da atual falta de saneamento rural no país em relação à implementação de uma proposta tecnológica de tratamento do esgoto, a fossa séptica biodigestora. Foi observado que, ao ano, a construção desse sistema de saneamento poderia evitar cerca de 250 mortes e 5,5 milhões de infecções causados por doenças diarreicas; reduzir a poluição dos cursos d’água em cerca de 129 mil toneladas de resíduos; e que cada $\mathrm{R} \$ 1,00$ investido na implementação da alternativa tecnológica avaliada poderia causar um retorno para a sociedade de $\mathrm{R} \$ 1,6$ em renda interna bruta. Além disto, a construção da fossa séptica biodigestora promoveria a geração de cerca de 39 mil empregos.
\end{abstract}

Palavras-chave: impacto socioeconômico; diarreia; população rural.

\begin{abstract}
Brazil has more than 23 million rural people with unimproved sanitation, which corresponds to about $75 \%$ of rural population. This study aimed to measure the social, environmental and economic impacts caused by the implementation of a technological proposal for sanitation, the septic cesspool biodigester. It was observed that, per year, the implementation of this technology in rural homes with unimproved sanitation could reduce about 250 deaths and 5.5 million infections caused by diarrheal diseases; reduce pollution of waterways by about 129 thousand tons of sediment; and that every $\mathrm{R} \$ 1.00$ invested in the implementation of the alternative technology evaluated could cause a return to the society of $\mathrm{R} \$ 1.6$ in gross domestic product. Moreover, the implementation of septic cesspool biodigesters would promote the creation of 39 thousand jobs.
\end{abstract}

Keywords: socioeconomic impact; diarrhea; rural population.

\section{INTRODUÇÃO}

O saneamento inclui um conjunto de atividades relacionadas ao tratamento de água e esgoto, coleta de lixo e práticas de higiene. Este trabalho teve como foco o tratamento de esgoto na área rural. Estima-se que apenas 25\% da população rural do país teve acesso à rede de coleta ou ao tratamento de esgoto em 2009 (IBGE, 2011a). Por outro lado, a população assistida com água tratada na área rural corresponde a 84\% (UNICEF, 2011). As diferenças nas condições da coleta de esgoto na área rural são ressaltadas quando observamos as diferentes regiões do país. Em 2009, enquanto nas regiões sul e sudeste 48 e 34\% da população rural, respectivamente, teve acesso à rede coletora de esgoto, as regiões Norte, Nordeste e Centro-Oeste apresentaram, respectivamente, 24, 16 e 9\% do esgoto coletado (IBGE, 2011a). Segundo o relatório da Organização Mundial da Saúde (OMS) (UNICEF/WHO, 2010), os percentuais observados na área rural dessas últimas regiões do país citadas são comparáveis aos de países da África subsaariana. O percentual de esgoto tratado na zona rural em Gana, por exemplo, foi de $38 \%$. Ressalta-se ainda que, enquanto mais de $50 \%$ da população brasileira com renda acima de 10 salários mínimos possui coleta de esgoto, cerca de apenas 15\% da população mais pobre o possui (IBGE, 2011a).

A falta de tratamento do esgoto sanitário doméstico traz várias consequências negativas para a sociedade. A literatura cita a saúde como a principal variável impactada pelas condições sanitárias da população. Nesse contexto, a consequência da falta de tratamento de esgoto, seja rural ou urbano, ocasiona diversas doenças, denominadas doenças feco-orais, que têm como marco principal as doenças

\section{口-}

'Doutora em Economia Aplicada. Pesquisadora da Embrapa Instrumentação - São Carlos (SP), Brasil.

${ }^{2}$ Doutor em Economia. Professor Titular do Departamento de Economia da Faculdade de Economia, Administração e Contabilidade da Universidade de São Paulo (USP) - São Paulo (SP), Brasil.

Endereço para correspondência: Cinthia Cabral da Costa - Embrapa Instrumentação - Rua XV de Novembro, 1452 - $13560-970$ - São Carlos (SP), Brasil -

E-mail: cinthia.cabral.da.costa@gmail.com

Recebido: 12/12/11 - Aceito: 08/04/14 - Reg. ABES: 171 
diarreicas (BALTAZAR et al., 1988; BRISCOE, 1987; ESREY, 1996; ESREY et al., 1985; ESREY et al., 1991; HELLER, 1997; OKUN, 1988). Além disso, cerca de $90 \%$ das mortes por diarreia são atribuídas às más condições sanitárias, como água, esgoto e higiene (UNICEF/ WHO, 2009). A diarreia foi também a maior causa de doenças no mundo em 2004, atingindo 4.620,4 milhões de pessoas em 2004. Outras grandes fontes de doenças no mundo seguem de longe com: 429,2 milhões de pessoas com infecções respiratórias; 241,3 milhões com malária e 9 milhões com dengue. No mesmo ano, ocorreram 2,16 milhões de mortes por diarreia no mundo, isto é, uma morte para cada 199 pessoas infectadas. No Brasil, o número de mortes em 2004 foi de 28.900 pessoas (WHO, 2008). ${ }^{1}$

Buscando melhorar a situação sanitária do país e, consequentemente, melhorar a saúde pública, a Lei 11.445/2007 e o decreto 7217/2010 estabelecem diretrizes para o saneamento básico no país (BRASIL, 2013). Nesses documentos, os cinco primeiros objetivos da Política Federal de Saneamento Básico listados são:

1. contribuir para o desenvolvimento nacional, a redução das desigualdades regionais, a geração de emprego e de renda e a inclusão social;

2. priorizar planos, programas e projetos que visem à implantação e ampliação dos serviços e ações de saneamento básico nas áreas ocupadas por populações de baixa renda;

3. proporcionar condições adequadas de salubridade ambiental aos povos indígenas e outras populações tradicionais, com soluções compatíveis com suas características socioculturais;

4. proporcionar condições adequadas de salubridade ambiental às populações rurais e de pequenos núcleos urbanos isolados;

5. assegurar que a aplicação dos recursos financeiros administrados pelo poder público se dê segundo critérios de promoção da salubridade ambiental, de maximização da relação benefício custo e de maior retorno social (BRASIL, 2013).

Mas qual seria a opção de saneamento para a área rural? A seguir são descritas e comparadas algumas opções e é justificada a análise realizada neste estudo sobre a alternativa da fossa séptica biodigestora.

Atualmente, na zona rural no Brasil, além da rede coletora, existem também o uso de fossa séptica, ligada ou não à rede de esgoto, as fossas rudimentares, entre outros (IBGE, 2011a). O mais comum é a fossa rudimentar (que serve $48 \%$ da população rural do país), a qual, juntamente com outros métodos e com a não coleta/tratamento, corresponde ao percentual da população rural não assistida com coleta

1 Aqui vale destacar que, neste trabalho foi utilizado o dado da OMS, e não a informação do Ministério da Saúde (BRASIL, 2011a; BRASIL, 2011b) pelo fato desses últimos não estarem de acordo com os dados da OMS. adequada do esgoto. São assim incluídas porque as fossas rudimentares não funcionam como forma de evitar a contaminação das águas superficiais e subterrâneas.

Assim, visando atender às necessidade de tratamento do esgoto rural, em função da expressiva população ali existente e da necessidade de melhorias, foi avaliado um sistema alternativo de tratamento, que é a fossa séptica biodigestora. A fossa séptica biodigestora foi desenvolvida por Novaes et al. (2006), no ano 2000. É um sistema de tratamento do esgoto de dejetos humanos, cujo intuito é substituir o esgoto a céu aberto e as atuais fossas utilizadas em propriedades rurais, em razão dos benefícios que podem ser gerados pela mesma (NOVAES et al., 2006). Os benefícios desse sistema em relação às fossas convencionais são, principalmente, a reciclagem dos dejetos e sua vedação hermética (que impede a proliferação de vetores de doenças). A Tabela 1 apresenta um resumo das principais características dos sistemas de fossa negra, fossa séptica e da fossa séptica biodigestora, essa última analisada neste trabalho, com o objetivo de se ter um melhor conhecimento sobre as opções existentes e justificar a opção avaliada.

Observa-se que, ao contrário da fossa séptica, as fossas rudimentares não funcionam como forma de evitar a contaminação das águas. Já a fossa séptica, apesar de evitar essa contaminação, não promove a reciclagem dos dejetos humanos, como ocorre na fossa séptica biodigestora. Essa última também elimina a contaminação de águas subterrâneas e, diferentemente dos outros métodos, promove a reciclagem dos dejetos. O produto dessa reciclagem é um

Tabela 1 - Comparação entre as opções de fossa para saneamento: características selecionadas.

\begin{tabular}{l|c|c|c} 
& $\begin{array}{c}\text { Fossa } \\
\text { rudimentar }\end{array}$ & $\begin{array}{c}\text { Fossa } \\
\text { séptica }\end{array}$ & $\begin{array}{c}\text { Fossa } \\
\text { séptica } \\
\text { biodigestora }\end{array}$ \\
$\begin{array}{l}\text { Contaminação } \\
\text { águas superficiais }\end{array}$ & $\operatorname{Sim}$ & Não & Não \\
\hline $\begin{array}{l}\text { Contaminação } \\
\text { águas subterrâneas }\end{array}$ & $\operatorname{Sim}$ & Não & Não \\
\hline $\begin{array}{l}\text { Necessidade de } \\
\text { retirar os dejetos }\end{array}$ & $\operatorname{Sim} /$ Não* & Sim & Não \\
\hline $\begin{array}{l}\text { Efluente reciclável } \\
\text { Todo esgoto } \\
\text { doméstico }\end{array}$ & Não & Não & Sim \\
\hline $\begin{array}{l}\text { Proliferação de } \\
\text { vetores }\end{array}$ & $\operatorname{Sim}$ & Sim & Não** \\
\hline Odor desagradável & $\operatorname{Sim}$ & Sim & Não \\
\hline $\begin{array}{l}\text { Vedação hermética } \\
\text { Não }\end{array}$ & Não & Sim \\
\hline
\end{tabular}

Fonte: Da Silva (2011), elaborado pela autora.

*Depende do tipo de solo: solos arenosos o material percola e não há necessidade.

**A fossa séptica biodigestora, ao contrário das outras, só trata o esgoto proveniente do vaso sanitário. Esgoto de ralos, tanques e pias não são coletados. 
efluente inodoro e com alta carga de nutrientes que são benéficos às plantas. Assim, o uso desse efluente pode ser utilizado diretamente para adubação de plantas localizadas próximas às residências, o que é muito comum na área rural, trazendo uma economia no consumo de fertilizantes químicos.

Como o sistema da fossa séptica biodigestora funciona sobre um processo de biodigestão anaeróbico. Para que isso ocorra, as caixas são vedadas, não há qualquer problema de proliferação de insetos e animais peçonhentos nos arredores da mesma, o que não ocorre com os outros dois sistemas comparáveis a ela. Assim, conclui-se que a fossa séptica biodigestora é um sistema de tratamento ambientalmente mais favorável para o ambiente rural. Como inconveniente, um sistema de tratamento auxiliar para tratamento do restante do esgoto doméstico deve ser realizado. Um sistema auxiliar, que contempla esse tratamento, foi desenvolvido com a denominação de "jardim filtrante" (LEONEL; MARTELLI; DA SILVA, 2013). Esse sistema tem como objetivo dar destino adequado à chamada "água cinza", que é aquela proveniente de pias, tanques e chuveiros.

Para melhor entendimento do processo da fossa séptica biodigestora, a Figura 1 ilustra seu funcionamento. A construção da fossa séptica biodigestora é descrita por Galindo et al. (2010) e um esquema resumido da mesma pode ser observado na Figura 1. A manutenção da estrutura apresentada nessa figura corresponde à colocação de esterco bovino fresco uma vez por mês na "válvula de retenção" (Figura 1). Não há necessidade de nenhuma outra atividade de manutenção, nem mesmo da retirada dos dejetos por caminhão apropriado, como ocorre com outros tipos de fossa.

Nesse cenário, o presente estudo propõe mensurar os impactos sociais, econômicos e ambientais da instalação da fossa séptica biodigestora como opção de tratamento sanitário pela população rural do país. Os resultados deste estudo são, portanto, uma contribuição científica que mensura alguns dos impactos descritos como objetivos da Política Federal de Saneamento Básico (Lei no 11.445/2007 e Decreto $\left.n^{\circ} 7217 / 2010\right)$. Tais análises de impacto constituem um poderoso instrumento para tomada de decisão de políticas públicas para melhoria das condições sociais e ambientais e, conforme descrito neste estudo, com impactos também econômicos.

\section{METODOLOGIA}

Para atingir os objetivos propostos neste estudo, os principais impactos mensurados foram: (A) redução no número mortes; (B) redução no número de pessoas doentes; $(\mathrm{C})$ redução na Demanda Bioquímica de Oxigênio (DBO) devido aos resíduos orgânicos provenientes do vaso

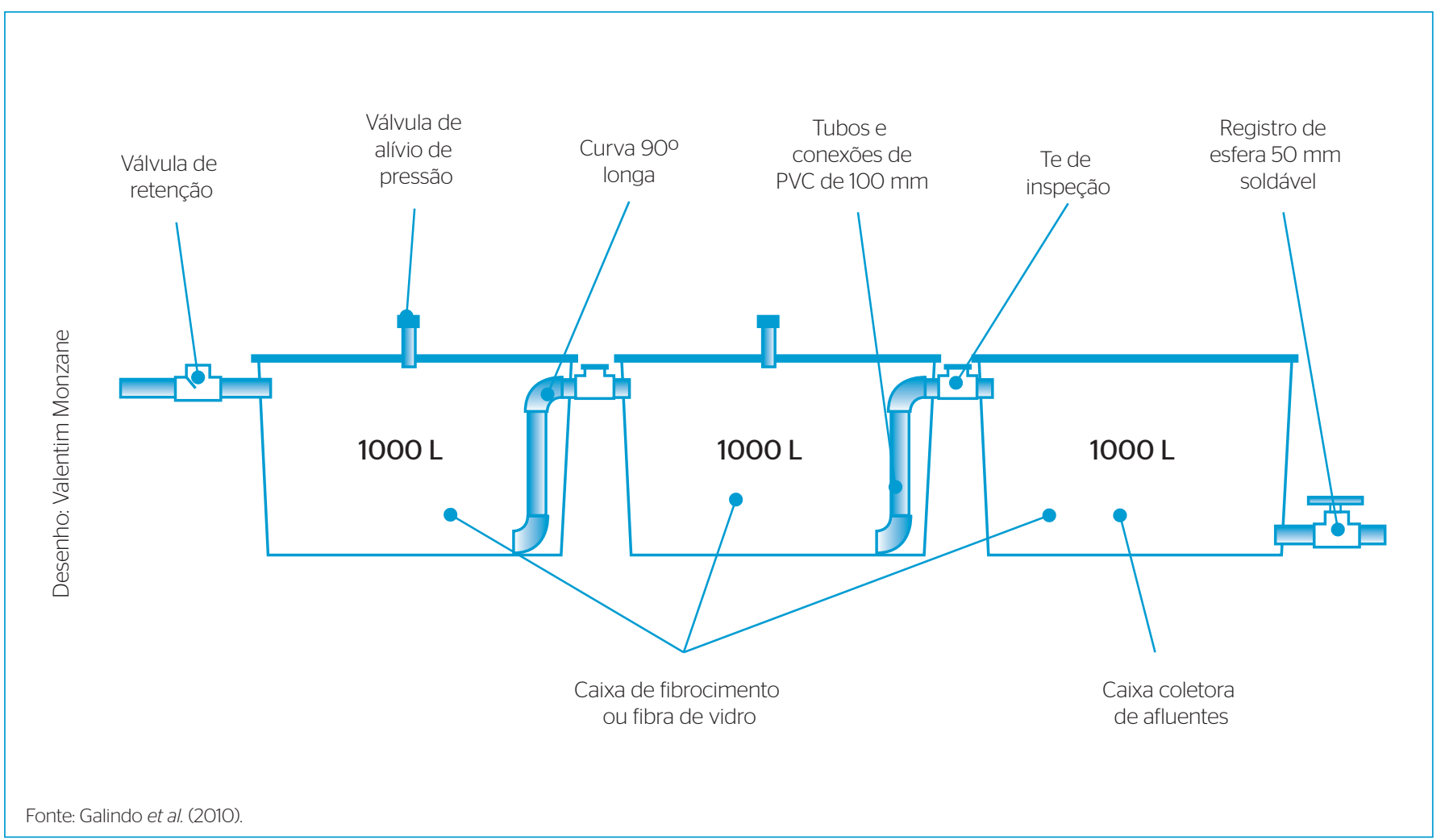

Figura 1 - Esquema do sistema da fossa séptica biodigestora. 
sanitário que deixariam de ser lançados nos cursos d'água; (D) redução no volume de nutrientes provenientes do vaso sanitário que deixariam de ser lançados nos cursos d'água; (E) redução nos gastos públicos com tratamento de doenças; (F) valor do Produto Interno Bruto (PIB) que deixaria de ser produzido em função da doença. Os itens (A) e (B) são indicadores sociais de impacto na saúde; os itens (C) e (D) são indicadores ambientais e os itens (E) e (F), indicadores econômicos. Esses últimos foram comparados com o custo de construção das fossas e analisados em duas etapas, sendo que na segunda etapa os impactos de transbordamento em toda economia brasileira foram identificados.

\section{Análise social}

O indicador de mortalidade (A) mostra a redução no número de óbitos que a melhoria nas condições sanitárias da população rural do país poderia provocar. Esse indicador foi identificado considerando o número de óbitos por diarreia por ano (óbitos), ponderado pela participação da população rural sem coleta de esgoto $\left(\mathrm{pop}_{\mathrm{ru}}\right)$ em relação à população total sem coleta de esgoto $\left(\operatorname{pop}_{\mathrm{ru}}+\mathrm{pop}_{\mathrm{urb}}\right)$, multiplicado pelo percentual de redução de mortes por diarreia causada por melhorias nas condições de tratamento de esgoto $(\alpha)$. A Equação 1 descreve esta relação:

$\mathrm{A}=\operatorname{obitos}^{\star}\left(\mathrm{pop}_{\mathrm{ru}} /\left(\mathrm{pop}_{\mathrm{ru}}+\mathrm{pop}_{\mathrm{urb}}\right)\right) \star \alpha$

Já o indicador de morbidade (B), ou seja, o número de pessoas que deixariam de adoecer pela melhoria nas condições sanitárias da população rural, foi estimado considerando o indicador de mortalidade (A) e o número de pessoas infectadas para cada óbito provocado pelas más condições sanitárias $(\beta)$. Algebricamente, o indicador de morbidade é descrito na Equação 2:

$\mathrm{B}=\mathrm{A} * 1 / \beta$

A redução na mortalidade (A) e na morbidade (B) corresponde ao período de um ano, uma vez que o número de óbitos foi obtido para um ano específico. As fontes dos dados e os valores utilizados para as variáveis descritas nas Equações 1 e 2 são apresentados na Tabela 1A do Anexo.

Obviamente, o fator qualidade da água está diretamente relacionado à sua condição de produzir doenças, como descrito anteriormente. Entretanto, a análise da qualidade ambiental da água leva em conta as características descritas na legislação brasileira (BRASIL, 2011c) e outras, além da contaminação microbiológica. Entre as características a serem analisadas que podem ser impactadas pelo lançamento do esgoto sanitário, que é o alvo desta análise, tem-se, além dos coliformes que causam os problemas de saúde discutidos anteriormente:
DBO; Oxigênio Disponível (OD); materiais flutuantes; $\mathrm{pH}$; e algumas substâncias potencialmente prejudiciais, como o fósforo e o nitrato. Essas características afetam diretamente a fauna aquática, uma vez que reduzem ou contribuem para a redução da disponibilidade de oxigênio na água. A seguir são apresentados os indicadores ambientais utilizados neste trabalho.

\section{Análise ambiental}

Foi estimada a redução no volume de resíduos sólidos, que reduzem a DBO do afluente da fossa, melhorando as condições sanitárias da população rural (C) em função da eliminação do efluente com menor carga poluidora. Para isso foi considerado, além da população rural não contemplada com coleta ou tratamento adequado do esgoto ( $\mathrm{pop}_{\mathrm{ru}}$ ), o volume de água, em litros, na descarga por pessoa/ ano ( vol $_{\text {agua }}$ ) e a DBO contida nesse esgoto. A população rural foi obtida em IBGE (2011a) como sendo de 23.019 pessoas. Quanto à composição dos dejetos da fossa séptica biodigestora, tem-se outra diferença entre esse tratamento e as demais fossas. Segundo dados descritos por Sperling (1998), a contribuição média de despejo de esgoto por uma pessoa por dia é de cerca de 120 litros, com DBO de $350 \mathrm{mg} . \mathrm{L}^{-1}, 0 \mathrm{mg}$ de OD e $1 \times 10^{8}$ de coliformes fecais. Entretanto, essas informações não foram utilizadas como parâmetro para avaliação da fossa séptica biodigestora porque o despejo de esgoto considerado por Sperling (1998) refere-se a todo esgoto doméstico, e a fossa aqui analisada é um sistema para tratamento apenas do esgoto do vaso sanitário. Assim, enquanto o volume de despejo por pessoa ao dia é menor, a DBO é maior do que a descrita por Sperling (1998). Segundo informações de Da Silva (2011, comunicação pessoal), é estimado um despejo de esgoto de cerca de 30 litros por pessoa por dia, com uma DBO entre 600 e $800 \mathrm{mg} . \mathrm{L}^{-1}$ (valor referente ao afluente da fossa). Já para o efluente desse sistema, segundo Faustino (2007), a DBO encontra-se entre 150 e 400 mg.L $L^{-1}$. Esses dados são também descritos na Tabela 1A do Anexo. A Equação 3 descreve essa relação, onde $\mathrm{C}$ quantifica a redução de $\mathrm{DBO}$ nos cursos d'água, considerando a carga de $\mathrm{DBO}$ do afluente $\left(\mathrm{DBO}_{\mathrm{a}}\right)$ e do efluente $\left(\mathrm{DBO}_{\mathrm{e}}\right)$ da fossa. Dividindo o valor calculado na Equação 3 por 1 bilhão, tem-se a carga de DBO em 1.000 ton/ano:

$\mathrm{C}=\operatorname{pop}_{\mathrm{ru}}{ }^{*} \operatorname{vol}_{\text {agua }} *\left(\mathrm{DBO}_{\mathrm{a}}-\mathrm{DBO}_{\mathrm{e}}\right)$

Outra questão importante relacionada ao impacto ambiental do tratamento do esgoto na área rural está relacionada à eutrofização dos cursos d'água. A eutrofização das águas é responsável pelo aspecto poluído dos cursos d’água, com coloração esverdeada pelo crescimento de algas (fitoplâncton) e aguapés. Além disso, tais organismos consomem oxigênio da água, reduzindo o oxigênio disponível e contribuindo ainda mais, além da DBO contida 
no esgoto, para piora da qualidade ambiental dos cursos d'água e morte da fauna aquática.

Para estimar a redução na concentração de nutrientes que deixariam de ser lançados nos cursos d'água (D) foi necessária a obtenção das seguintes variáveis: população rural não contemplada com coleta ou tratamento adequado do esgoto ( pop $_{\mathrm{ru}}$ ); volume de água, em litros, na descarga por pessoa/ano ( vol $_{\text {agua }}$ ); e concentração de nutrientes contidos por litro do efluente gerado pela fossa séptica biodigestora $(\mathrm{N}+\mathrm{K}+\mathrm{P})$, em mg. $\mathrm{L}^{-1}$, onde $\mathrm{N}$ indica o volume de nitrogênio, $\mathrm{K}$ o volume de potássio e $\mathrm{P}$ o volume de fósforo. Conforme descrito na Tabela 1A do Anexo, para essa última variável, Faustino (2007) identificou a concentração média de 500; 75 e 120 mg.L L $^{-1}$, respectivamente, para N, P e K. Assim, esse indicador foi estimado conforme descrito na Equação 4:

$\mathrm{D}=(\mathrm{N}+\mathrm{K}+\mathrm{P}){ }^{*}$ pop $_{\mathrm{ru}}{ }^{*} \mathrm{vol}_{\text {agua }}$

Dividindo o valor calculado na Equação 4 por 1 bilhão, tem-se a quantidade de nutrientes em 1.000 ton/ano. Entretanto, esses mesmos nutrientes descritos anteriormente como nocivos aos cursos d'água por promoverem sua poluição são, por outro lado, muito úteis para o crescimento e produção das plantas. Tais elementos são os principais componentes dos fertilizantes agrícolas. Dessa maneira, uma vez que a fossa é proposta para ser construída na área rural, cuja principal atividade econômica é a produção agrícola, e o processo anaeróbico da fossa séptica biodigestora não elimina tais elementos químicos, eles podem ser aproveitados na adubação de lavouras, com economia no uso de fertilizantes químicos. Além disso, o efluente da fossa promove melhoria do $\mathrm{pH}$ do solo e contém micronutrientes que podem aumentar a produtividade. Apesar desses benefícios econômicos possíveis, esse fator não foi mensurado no presente trabalho, uma vez que cuidados adicionais e, consequentemente, custos adicionais em relação ao uso desse efluente para a adubação de lavouras devem ser analisados individualmente para cada propriedade rural e, portanto, podendo tornar não realista uma mensuração geral.

\section{Análise econômica}

A redução nos gastos públicos com tratamento das doenças (E) foi estimada considerando um valor médio deste tratamento $\left(\mathrm{P}_{\text {trat }}\right)$ multiplicado pelo número de doenças evitadas (B) e pelo percentual de pessoas doentes que recebem tratamento $(\delta)$. A Equação 5 descreve esse cálculo:

$\mathrm{E}=\mathrm{P}_{\text {trat }} * \mathrm{~B} * \delta$

A fonte dos dados e os valores utilizados para todas as variáveis descritas na Equação 5 são apresentados na Tabela 1A do Anexo.
Em relação ao valor do PIB que deixaria de ser produzido em função da doença (F), buscou-se valorar os retornos obtidos pela instalação das fossas para a sociedade. Para isso foi utilizada a abordagem do custo da doença e considerou-se apenas a morbidade, ou seja, não foram valoradas as mortes causadas. Nesse sentido, a abordagem do custo aplicado à morbidade pode ser dividida em duas categorias: despesas médicas para tratamento da doença e perdas de salários durante os dias de hospitalização, falta no trabalho e outros dias, quando as atividades econômicas são reduzidas devido à doença (SALDIVA et al., 2010). Essa segunda categoria é baseada no método desenvolvido pela OMS chamado Disability Adjusted Life Years (DALY). O valor de uma DALY representa a perda equivalente a um ano com saúde (UNICEF/WHO, 2010). Neste trabalho foi utilizada a abordagem do custo aplicada à morbidade e o indicador de anos de vida (DALY) foi convertido em base monetária multiplicando esse valor pelo PIB per capita anual do país. Algebricamente, o PIB que deixar de ser produzido em função da doença (F) é descrito na Equação 6 e a fonte e valores utilizados são apresentados na Tabela $1 \mathrm{~A}$ do Anexo.

$\mathrm{F}=\mathrm{DALY}^{\star} \alpha^{\star} \mathrm{PIB}_{\text {per capita }}$

Os valores obtidos nas Equações 5 e 6 foram então comparados ao valor da instalação da fossa séptica biodigestora. Esse último foi calculado multiplicando seu custo unitário pela população rural não contemplada com coleta ou tratamento adequado do esgoto ( pop $_{\mathrm{ru}}$ ) divida por cinco (número médio estimado de pessoas em uma família). Como os valores das variáveis $\mathrm{D}, \mathrm{E}$ e F são anuais, o valor da construção das fossas foi também dividido pela sua vida útil (vu). Assim, tem-se uma estimativa anual dos gastos necessários para atender à população rural do país sem tratamento adequado do esgoto. O cálculo deste valor é descrito na Equação 7 e a fonte e valores utilizados são apresentados na Tabela 1A do Anexo.

Custo da fossa $=$ custo unitário $\mathrm{x}\left(\operatorname{pop}_{\mathrm{ru}} / 5\right) \mathrm{x} \mathrm{vu}$

Os impactos econômicos descritos anteriormente, entretanto, não consideram os efeitos de transbordamento que se tem na sociedade ao modificarmos alguma variável econômica. Assim, uma segunda etapa da análise econômica foi realizada com objetivo de estimar os encadeamentos provocados na economia pelas estimativas econômicas desses impactos. A seguir é descrito o método utilizado para tal avaliação.

\section{Análise econômica sobre a sociedade brasileira}

Para a análise dos impactos na economia brasileira foi utilizado o instrumental de avaliação da matriz insumo produto, que considera todos os 
encadeamentos entre os setores da economia. Assim, com esse instrumental podemos identificar os impactos de transbordamento de um choque de demanda qualquer sobre a produção de toda a economia analisada. A partir desse impacto na produção podem ser estimados impactos também no PIB, no emprego, no valor das remunerações e nas importações de toda economia. Esses impactos são provenientes dos choques diretos aplicados, assim como os efeitos indiretos provocados em outros setores, conforme metodologia descrita por Miller e Blair (2009).

Na situação a ser avaliada neste trabalho os seguintes choques ocorreram na economia: (i) aumento na demanda dos setores relacionados à construção da fossa séptica biodigestora apresentada no item anterior; e (ii) aumento na demanda final das famílias ocasionado pelo aumento no PIB em função da redução nas DALYs, ponderado pela receita das famílias utilizada para o consumo ${ }^{2}$. Além disso, a economia do setor de saúde pública pode ser utilizada para melhoria nesse próprio setor. Esse item, entretanto, não foi considerado como um choque na economia neste trabalho.

Os choques descritos naqueles itens são alterações na demanda final da economia. Os impactos foram calculados utilizando a matriz insumo produto do Brasil do ano de 2008, estimada com base nas tabelas de produção e de recursos e usos das Contas Nacionais do país naquele ano (GUILHOTO \& SESSO FILHO, 2005; IBGE, 2011b).

\section{RESULTADOS}

Assim como foi apresentado nos métodos, este item foi divido em três partes: estimativas de impacto social (número de mortes e doenças evitadas pela melhoria da condição sanitária); estimativa de impacto ambiental (volume de poluentes que deixaram de ser despejados nos cursos d'água); e estimativa de impacto econômico (custo das instalações das fossas; perdas econômicas decorrentes dos impactos sociais). Para isso, calculou-se os impactos estimados nas Equações 1 a 7 descritos anteriormente. Entretanto, inicialmente foi necessário estimar os valores dos parâmetros identificados naquelas equações. Esses valores foram obtidos de revisões bibliográficas e descritos na Tabela $1 \mathrm{~A}$ do Anexo. A partir desses dados foram estimados os possíveis impactos da instalação de fossas sépticas biodigestoras em toda a população rural não assistida com coleta ou tratamento adequado do esgoto. Essas estimativas são descritas na Tabela 2

\section{Estimativa de impacto social}

Em relação à característica social, estima-se que com a melhoria no sistema sanitário da área rural do país haja uma redução de cerca de
Tabela 2 - Valores anuais dos impactos sociais, ambientais e econômicos da instalação de fossas sépticas biodigestoras na população rural com tratamento sanitário inadequado.

\begin{tabular}{l|c|c}
\hline Análise social & Indicador & $\begin{array}{c}\text { Número } \\
\text { de pessoas }\end{array}$ \\
\hline $\begin{array}{l}\text { Redução anual das } \\
\text { mortes por diarreia }\end{array}$ & A & 2.592 \\
\hline $\begin{array}{l}\text { Redução anual das } \\
\text { doenças diarreicas }\end{array}$ & B & 5.544 .779 \\
\hline Análise ambiental & $\begin{array}{c}1.000 \\
\text { toneladas }\end{array}$ \\
\hline $\begin{array}{l}\text { Redução da carga } \\
\text { de demanda bioquímica } \\
\text { de oxigênio lançada }\end{array}$ & C & 129 \\
\hline $\begin{array}{l}\text { Redução da carga } \\
\text { de nutrientes lançados }\end{array}$ & & 173 \\
\hline $\begin{array}{l}\text { Análise econômica } \\
\text { Custo anual de instalação das fossas }\end{array}$ & & 647 \\
\hline Ganhos & E reais \\
\hline $\begin{array}{l}\text { Realocação nos gastos de saúde } \\
\text { Ganhos de PIB anual por causa da } \\
\text { doença evitada }\end{array}$ & F & 7677 \\
\hline
\end{tabular}

2.592 mortes e 5,5 milhões de casos de doenças diarreicas por ano (Tabela 2). Esse é um impacto de grande importância social, uma vez que preserva vidas humanas as quais, na sua maioria, são de crianças de menos de cinco anos de idade.

Comparando esses números com outras doenças, tem-se que o número de casos novos de dengue no Brasil em 2008 foi de 556.224 (BRASIL, 2011d). Ou seja, 10\% do número de casos de doenças diarreicas. Já o número de mortes por meningite no Brasil em 2004 foi um pouco menor do que o número de mortes evitadas por diarreia descrita anteriormente: 4,4 milhões de pessoas (WHO, 2008).

O número de casos de doenças diarreicas evitados obtido neste trabalho pode ser comparado ao número encontrado no estudo de Hutton et al. (2007), os quais calcularam o número dessas doenças evitadas (assim como o de mortes) para vários grupos de países em desenvolvimento, em decorrência do acesso universal a água tratada e saneamento básico ${ }^{3}$. No grupo onde se encontra o Brasil, composto de 26 países das Américas do Sul e Central, o número de casos de doenças diarreicas evitados foi de 197,6 milhões. Para o número de mortes evitadas, esses autores não apresentaram valores por regiões, apenas o total mundial. A diferença entre o número de

2 Ou seja, não foi considerado como aumento de demanda final o percentual que as famílias poupam desse aumento no PIB. Segundo informações das Contas Nacionais de 2006, o percentual do PIB consumido pelas famílias foi de 71,6\%.

3 Hutton et al. (2007) analisaram quatro diferentes cenários. O cenário descrito para a comparação dos resultados obtidos por esses autores com o presente estudo foi aquele que se apresentou mais próximo ao caso estudado neste trabalho. 
doenças evitadas obtido por Hutton et al. (2007) e por este estudo (197,6 milhões e 5,5 milhões, respectivamente) deve-se ao fato de que os primeiros analisaram: (i) maior número de países; (ii) toda população sem acesso e não apenas a população rural; e (iii) além do tratamento de esgoto, também o acesso à água tratada. Entretanto, procurando desconsiderar os parâmetros (i) e (ii), foi procedida uma comparação dos resultados obtidos neste estudo em termos percentuais. Assim, a população não assistida com os tratamentos considerada no supracitado trabalho foi de 531 milhões, ou seja, o percentual de casos de doenças diarreicas evitadas por ano foi de $37 \%$ daquela população, superior ao valor de $23 \%$ obtido no presente trabalho, possivelmente pela não inclusão do acesso à água tratada na nossa avaliação.

\section{Estimativa de impacto ambiental}

No caso dos impactos ambientais, uma vez que a fossa séptica biodigestora reduz cerca de $65 \%$ da $\mathrm{DBO}^{4}$, mesmo que seu efluente seja lançado nos cursos d’água, isso significaria uma redução de 129 mil toneladas de resíduos (Tabela 2). Entretanto, se todo o efluente for utilizado para fertilização de culturas agrícolas, não haveria qualquer descarga dos resíduos nas águas, e a redução poderia atingir 200 mil toneladas de resíduos sólidos ao ano.

Ainda seriam reduzidos nutrientes que causam eutrofização das águas. O volume equivalente dessa redução foi calculado em 124 mil toneladas de nitrogênio; 18,6 mil toneladas de fósforo e 29,8 mil toneladas de potássio (Tabela 2).

Não foram encontrados, no caso dos impactos ambientais descritos neste trabalho, outros estudos para comparar os resultados obtidos. Além disso, observou-se uma carência de estudos relacionados à correlação entre as variáveis que promovem a poluição provocada pelos dejetos humanos (resíduos sólidos e nutrientes) sobre variáveis mais ligadas ao impacto sobre a população. Por exemplo, o quanto essa poluição impacta a mortalidade de peixes para alimentação humana.

Apesar de procurar abranger as três esferas da sustentabilidade, este estudo teve um foco maior na análise econômica, como pode ser observado nos resultados apresentados a seguir.

\section{Estimativa de impacto econômico}

Quanto ao investimento necessário para construção da fossa, tem-se o custo total estimado em $\mathrm{R} \$ 647$ milhões ao ano, considerando sua vida útil de 10 anos (Tabela 2). Esse valor é comparável ao recurso financeiro investido na prevenção da dengue pelo controle do inseto vetor no país, que, segundo dados de Ministério da Saúde (BRASIL,

4 Ver valores de DBO do afluente e do efluente da fossa séptica biodigestora descrito na Tabela $1 \mathrm{~A}$ 2011d), foram de cerca de R\$ 700 milhões em 2009. Entretanto, o número de mortes no país por dengue foi de apenas 400, ou seja, $1,4 \%$ do número de mortes provocadas por doenças diarreicas no país no mesmo ano (OMS, 2004). Considerando que o investimento nas fossas sépticas ainda apresenta benefícios ambientais e econômicos para o produtor rural, tal investimento pode causar retornos para a sociedade ainda superiores aos que poderiam ser obtidos pelo controle do Aedes aegypti (inseto vetor da dengue). Isso não significa dizer que o Ministério da Saúde deve deixar de investir no controle da dengue para investir no controle da diarreia na zona rural, mas sim que ambos devem ser tratados com igual importância, o que não é observado, visto o alto percentual da população rural sem tratamento ou com tratamento de esgoto precário.

Já os gastos com saúde para cuidar dos casos de diarreia foi estimado, individualmente, pelo percentual do gasto do Ministério da Saúde com atenção básica e os valores per capita dos gastos com saúde federal, estadual e municipal no valor de R \$ 83,71 per capita. Entretanto, apenas $28 \%$ das crianças com diarreia recebem tratamento (UNICEF, 2011). Assim, o tratamento do esgoto rural ainda não tratado originaria, considerando apenas o percentual de crianças tratadas, uma economia de recursos na área de saúde de $\mathrm{R} \$ 130$ milhões (que corresponde a 20\% do custo anual de instalação das fossas), que podem ser canalizados para tratamento de outras doenças melhorando as condições de saúde da população e reduzindo ainda mais o número de anos improdutivos ocasionados por outras doenças (DALY).

Transformando ainda esse número de doenças diarreicas evitadas em DALYs (anos improdutivos) evitados, considerando apenas as perdas por doença (ou seja, foram retirados da conta o número de DALYs referentes à morte prematura), tem-se um total de 38 mil anos evitados pelo tratamento das fossas estimado neste trabalho. Uma vez que as doenças diarreicas atingem mais as crianças, essas perdas ocasionam perdas escolares ou de trabalho dos pais que precisam cuidar de seus filhos. Entretanto, foi utilizada como uma maneira de mensurar tais perdas, o PIB per capita do país para 2009. Assim, obteve-se um valor de $\mathrm{R} \$ 637,28$ milhões para tais perdas provocadas pela doença ( $98 \%$ do custo anual de instalação das fossas).

Assim, o custo-benefício econômico estimado para essa primeira etapa da análise econômica foi de 1,2, valor bem inferior ao valor de 40,7 obtido por Hutton et al. (2007). Além das diferenças já mencionadas anteriormente, contribuiu também a diferença nos métodos utilizados em ambos os estudos, como por exemplo os impactos econômicos do número de mortes evitadas e do tempo economizado pelas facilidades introduzidas.

\section{Impactos econômicos na sociedade brasileira}

Como descrito anteriormente, para obter uma análise dos impactos sobre a economia brasileira da fossa séptica biodigestora como 
tratamento sanitário para a população rural, deve-se considerar os valores de choques nos principais setores impactados por essa tecnologia. Os valores foram transformados em preços básicos retirando os percentuais relativos às margens de transporte, comércio e impostos sobre os produtos. Esses percentuais são obtidos na planilha de produção de 2008 do IBGE (IBGE, 2011b). Apenas no setor de demanda final das famílias o preço pago ao consumidor não foi transformado, pois o valor da economia feita é a preço de consumidor. Em relação ao valor de R 637 milhões adicionados em PIB causados pela doença evitada na economia, tem-se também que nem todo PIB recebido pelas famílias é consumido (parte é poupado). Assim, considerou-se o percentual da Renda Disponível Líquida das Famílias (consumo final e investimento) no valor do PIB da economia calculado com base na CEI para o ano de 2006 (dado mais recente). Esse percentual foi de 71,6\% (IBGE, 2011b). Assim, do valor de R\$ 637 milhões adicionados em PIB de doença evitada na economia, as famílias irão gastar o equivalente a $\mathrm{R} \$ 456,4$ milhões.

Portanto, os choques feitos na matriz insumo produto da economia foram: (i) aumento na demanda das famílias no montante equivalente ao aumento no PIB proveniente do ganho de anos produtivos pela redução na DALY - R\$ 456 milhões (percentual consumido pelas famílias no total de aumento de renda de R 637 milhões) e (ii) aumento dos gastos do governo para construção da fossa, a preços básicos ${ }^{5}$, dividido da seguinte maneira entre os setores da economia: $49 \%$ para o setor "outros produtos de minerais não metálicos" (R\$232,49 milhões); 46\% para o setor "artigos de borracha e plásticos" (R\$240,04 milhões); 1\% para o setor “tintas, vernizes, esmaltes e lacas" (R\$ 5,75 milhões); e 3\% para o setor "produtos e preparados químicos diversos" (R\$ 18,52 milhões).

Os valores dos impactos sobre o valor da produção da economia brasileira, considerando os impactos diretos e indiretos produzidos pelos choques, são descritos na Tabela 3.

Assim, além das mortes e da poluição evitada, a cada ano (considerando a tecnologia fixa, referente ao ano de 2008) os choques poderiam aumentar o PIB do país em mais de R\$ 1.046 milhões; aumentar a remuneração dos empregados em cerca de R 465 milhões; e criar mais de 39 mil novos postos de emprego. Já o aumento no valor das importações em R 158 milhões é um aspecto negativo desse aumento de renda. Subtraindo do custo anual com a construção das fossas ( $\mathrm{R}$ 647 milhões) o aumento no valor da produção da economia

\footnotetext{
5 É uma condição imposta pelo método da análise da matriz insumo produto que os preços de aumento de demanda por bens seja a preços básicos e não a preços de mercados. Preços básicos não consideram as margens de comércio e transporte no preço final. Por esse motivo, a soma dos valores descritos como choque de demanda final ( $\mathrm{R} \$ 496,7$ milhões) é $23 \%$ inferior ao valor estimado para a construção das fossas (R\$ 647 milhões).
}

Tabela 3 - Impactos diretos e indiretos dos choques realizados sobre a economia brasileira (milhões de reais).

\begin{tabular}{l|c|c|c|c}
$\begin{array}{l}\text { Valor bruto } \\
\text { da produção }\end{array}$ & Remuneração & PIB & Importação & $\begin{array}{c}\text { Emprego } \\
\text { (número) }\end{array}$ \\
\hline 2.429 & 465 & 1.046 & 158 & 39.203 \\
\hline
\end{tabular}

( R 2.429 milhões), tem-se que a economia tem um ganho líquido de R\$ 1.782 milhões.

Portanto, considerando apenas algumas variáveis mensuráveis economicamente do item anterior, foi estimado que a cada $\mathrm{R} \$ 1,00$ investido na construção das fossas na área rural o retorno é de R\$ 1,2. Entretanto, considerando os encadeamentos na economia, esse retorno passa a ser de $\mathrm{R} \$ 3,75$. Em termos de ganhos de renda, a cada $\mathrm{R} \$ 1,00$ investido tem-se um retorno de R\$ 1,61 em PIB. Não foram encontrados outros estudos com análises similares, sendo assim uma comparação direta não pode ser realizada. Entretanto, observa-se que apenas considerando o retorno para toda a sociedade dos investimentos e ganhos de valor da produção provocados pela melhoria das condições sanitárias do ambiente rural é que o custo-benefício analisado neste estudo $(3,75)$ se aproxima da relação obtida Hutton, Haller e Bartram (2007), considerando apenas os impactos diretos do saneamento.

Diante desse cenário positivo da implementação da fossa séptica biodigestora pelos órgãos públicos na área rural do país, a seguir são elaboradas algumas conclusões e recomendações gerais extraídas deste estudo.

\section{CONCLUSÃO}

O presente estudo aponta retornos econômicos favoráveis para a economia em função de gastos em saneamento, mesmo para tecnologias mais simples disponíveis para a área rural. Encontrou-se que, ao ano, a construção desse sistema de saneamento poderia reduzir cerca de 250 mortes e 5,5 milhões de infecções causadas por doenças diarreicas; reduzir a poluição dos cursos d'água em cerca de 129 mil toneladas de resíduos e que cada $\mathrm{R} \$ 1,00$ investido na implementação da alternativa tecnológica avaliada poderia causar um retorno para a sociedade de R\$ 1,6 em renda interna bruta. Além disso, ocorreria um aumento de 39 mil empregos.

Ganhos adicionais ainda podem ser obtidos caso seja utilizado o efluente gerado nesse sistema para fertilização de culturas agrícolas, os quais não foram inseridos na presente análise. Entretanto, nesse tópico identificou-se a necessidade de mais estudos sobre o efeito do efluente no solo e na produção agrícola, assim como a disseminação dessas informações para os usuários da fossa. 


\section{REFERÊNCIAS}

BALTAZAR, J.; BRISCOE, J.; MESOLA, V.; M.O.E.C:; SOLON, F.; VANDERSLICE, J.; YOUNG, B. (1988) Can the case-control method be used to assess the impact of water supply and sanitation on diarrhoea? A study in the Philippines. Bulletin of the World Health Organization, v. 66, n. 5, p. 627-635.

BRASIL. (2011a) Ministério da Saúde. Indicadores de Morbidade. Disponível em: http://tabnet.datasus.gov.br/cgi/tabcgi.exe?idb2009/ dO201.def. Acesso em 20 jan. 2011.

BRASIL. (2011b) Ministério da Saúde. Indicadores de Mortalidade. Disponível em: http://tabnet.datasus.gov.br/cgi/tabcgi.exe?idb2009/c14. def. Acesso em 20 jan. 2011.

BRASIL. (2011c) Ministério do Meio Ambiente. Resolução CONAMA no 20, de 18 de junho de 1986. Disponível em: http://www.mma.gov.br/ port/conama/res/res86/res2086.html. Acesso em 31 jan. 2011.

BRASIL. (2011d) Ministério da Saúde. Disponível em: http://portal.saude. gov.br/portal/arquivos/pdf/informe_epidemiologico_semana_1a52_09_ revisado.pdf. Acesso em 08 fev. 2011.

BRASIL. (2013) Presidência da República Federativa do Brasil. Casa Civil. Decreto no 7.217, de 21 de junho de 2010. Regulamenta a Lei no 11.445, de 5 de janeiro de 2007, que estabelece diretrizes nacionais para o saneamento básico, e dá outras providências. Disponível em: http:// www.planalto.gov.br/ccivil_03/_ato2007-2010/2010/Decreto/D7217.htm. Acesso em 23 maio 2013.

BRISCOE, J. (1987) Abastecimiento de agua y servicios de saneamento: su funcion em la revolucion de la supervivencia infantil. Boletín de la Oficina Sanitaria Panamericana, v. 103, n. 4, p. 325-339.

DA SILVA, W.T.L. (2011). Comunicação pessoal.

ESREY, S.A. (1996) Water, waste, and well-being: a multicountry study. American journal of Epidemiology, v. 143, n. 6, p. 608-623.

ESREY, S.A.; FEACHEM, R.G.; HUGHES, J.M. (1985) Interventions for the control of diarrhoeal diseases among young children: improving water supplies and excreta disposal facilities. Bulletin of the World Health Organization, v. 63, n. 4, p. 757-772.

ESREY, S.A.; POTASH, J.B.; ROBERTS, L.; SHIFF, C. (1991) Effects of improved water supply and sanitation on ascariasis, diarrhea, dracunculiasis, hookworm infection, schistosomiasis, and trachoma. Bulletin of the World Health Organization, v. 69, n. 5, p. 609-621.

FAUSTINO, A.S. (2007) Estudos físico-químicos do efluente produzido por fossa séptica biodigestora e o impacto do seu uso no solo. Dissertação (Mestrado), Universidade Federal de São Carlos.

GALINDO, N.; DA SILVA, W.T.L.; NOVAES, A.P.; GODOY, L.A.; SOARES, M.T.S.; GALVANI, F. (2010). Perguntas e respostas: fossa séptica biodigestora. Série Documentos. N. 49. São Carlos: Embrapa.

GUILHOTO, J.J.M. \& SESSO FILHO, U.A. (2005) Estimação da matriz insumo-produto a partir de dados preliminares das Contas Nacionais. Economia Aplicada, v. 9, n. 2, p. 277-299.
HELLER, L. (1997) Saneamento e saúde. Brasília: OPAS.

HUTTON, G.; HALLER, L.; BARTRAM, J. (2007). Global cost-benefit analysis of water supply and sanitation interventions. Journal of Water and Health, v. 5, n. 4, p. 481-501.

IBGE - Instituto Brasileiro de Geografia e Estatística. (2011a) Pesquisa Nacional por Amostra de Domicílios. Banco da Dados Agregados (PNAD). Disponível em: http://www.sidra.ibge.gov.br/pnad/pnadpb. asp?o=3\&i=P. Acesso em 20 jan. 2011.

IBGE - Instituto Brasileiro de Geografia e Estatística. (2011b) Disponível em: http://www.ibge.gov.br/home/default.php. Download. Estatísticas. Contas Nacionais. Sistemas de Contas Nacionais. 2008. Acesso em 15 fev. 2011.

LEONEL, L.F.; MARTELLI, L.F.A.; DA SILVA, W.T.L. (2O13) Avaliação do efluente de fossa séptica biodigestora e jardim filtrante. In: III Symposium on Agricultural and Agroindustrial Waste Management. São Pedro, São Paulo.

MILLER, R.E. \& BLAIR, P.D. (2009). Input-output analysis: foundations and extensions. 2 ed. Cambridge: Cambridge University Press.

NOVAES, A.P.; SIMÕES, M.L.; INAMASU, R.Y; JESUS, E.A.P.; MARTINNETO, L.; SANTIAGO, G.; DASILVA, W.T.L. (2006) Saneamento básico na área rural. In: SPADOTTO, C. \& RIBEIRO, W. (Org.). Gestão de resíduos na agricultura e na agroindústria. Botucatu: Fundação de Estudos e Pesquisas Agrícolas e Florestais. p. 262-275.

OKUN, D.A. (1988) The value of water supply and sanitation in development: an assessment. American Journal of Public Health, v. 78, n. 11, p. 1463-1467.

SALDIVA, P.H.N.; ANDRADE, M.F.; MIRAGLIA, S.G.E.K.; ANDRÉ, P.A. (2010), O etanol e a saúde. In: SOUZA, E.L.L. \& MACEDO, I.C. (Org.). Etanol e bioeletricidade: a cana-de-açúcar no future da matriz energética. São Paulo: Luc, pp. 226-259.

SPERLING, M.V. (1998) Análise dos padrões brasileiros de qualidade de corpos d’água e de lançamentos de efluentes líquidos. Revista Brasileira de Recursos Hídricos, vol. 13, n. 1, p. 111-132.

UNICEF - The United Nations Children's Fund (2011). Estatística de saúde. Disponível em: http://www.unicef.org/sowc09/statistics/tables. php. Acesso em 10 mar. 2001.

UNICEF/WHO - The United Nations Children's Fund/World Health Organization. (2009) Diarrhoea: why children are still dying and what can be done. Genebra: World Health Organization.

UNICEF/WHO - The United Nations Children's Fund/World Health Organization (2010). Progress on sanitation and drinking-water: 2010 update. France: World Health Organization.

WHO - World Health Organization (2008). The global burden of disease: 2004 update. Genebra: World Health Organization. 


\section{Anexo}

Tabela 1 A - Valores dos parâmetros utilizados para estimar os impactos sociais, ambientais e econômicos da instalação da fossa séptica biodigestora para a população rural do Brasil sem coleta/tratamento de esgoto.

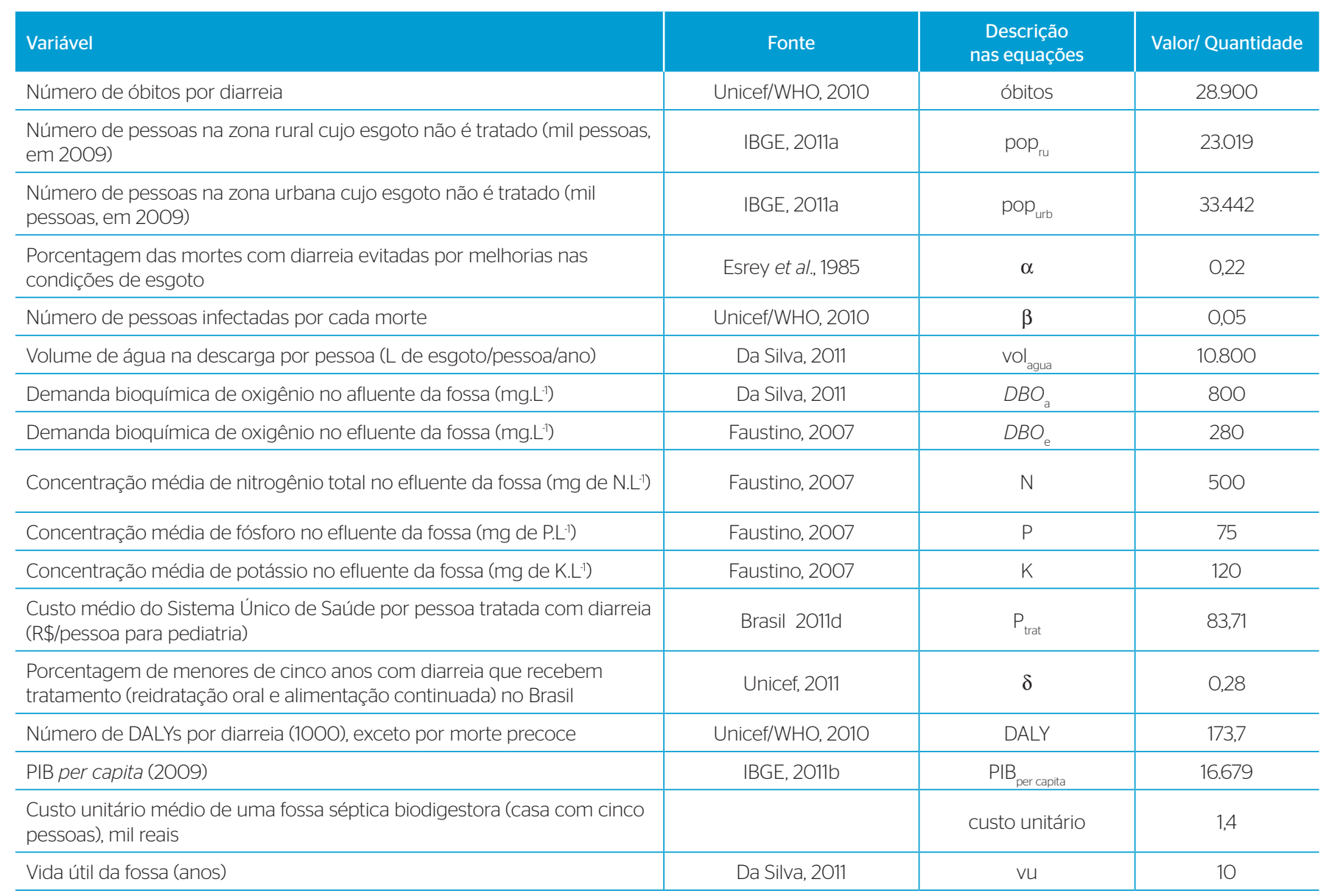

